\title{
Curriculum Development
}

\author{
K Kranthi \\ Department of English, Bharat Institute of engineering \& Technology College,Ibrahimpatnam-, Hyderabad \\ (India)
}

\begin{abstract}
The study is about curriculum development, importance of curriculum development and guide to Curriculum Development: Purposes, Practices, and Procedures in higher education. Previous studies have shown that curriculum development today is exposed to different pressures to respond to demands in labour markets and in society at large. Less is known about how faculty members engage in curriculum development and how their ways of engaging are related to their understandings of curriculum, and their teaching and research experiences. This research investigates how curriculum is understood in history as a discipline and how the faculty members engage themselves in its development. It also seeks answer of how faculty members' understandings of curriculum, and their teaching and research experience influence their curriculum development work.
\end{abstract}

Key words: Curriculum, Curriculum Development, Academic Plan, Faculty Members, Higher Education, design, methodology, originality, value.

\section{INTRODUCTION:}

Curriculum development is a vital component in the educational process. Its scope is exceptionally broad, and it involves nearly everyone who is involved with teaching and learning. Curriculum development resources offer guidance for lesson plan preparation that meets the educational standards set by each state. Resources for curriculum development for teachers are abundant, with resources being offered both electronically and in print, freely available and for purchase. Design/methodology/approach - Curriculum development resources were chosen based on the selection criteria included in the article, including: authority, accuracy, scope, appropriateness, and treatment. There were many resources for teachers available, but only a few were selected. Those selected met the selection criteria and were outstanding and beneficial resources for curriculum development. Findings - Resources for curriculum development for teachers are abundant, with resources being offered both electronically and in print, freely available and for purchase. Perhaps in the upcoming years, as information literacy instruction becomes part of more institutions; further resources will be made available. Originality/value - the function of curriculum development is to research, plan, and prepare the content and methods that will be taught during instruction to achieve the desired outcomes. State curriculum standards currently play a major role in schools and how the curriculum is developed. Curriculum development resources provide the necessary resources for teachers to plan and prepare curricula that can meet the standards set by each state.

\section{WHAT IS CURRICULUM?}

A curriculum is considered as the "heart" of any learning institution which means that schools or universities cannot exist without a curriculum. With its importance in formal education, the curriculum has become a dynamic process due to the changes that occur in our society. Therefore, in its broadest sense, curriculum refers to the "total learning experiences of individuals not only in school but society as well".

\section{Definition of Curriculum Development}

Curriculum development is defined as planned, a purposeful, progressive, and systematic process to create positive improvements in the educational system. Every time there are changes or developments happening around the world, the school curricula are affected.

\section{Importance of Curriculum Development}

Curriculum development has a broad scope because it is not only about the school, the learners, and the teachers. It is also about the development of society in general. There must be a chain of developmental process to develop a society. First, the school curriculum, particularly in higher education, must be developed to preserve the country's national identity and to ensure its economy's growth and stability. 
If universities have curricular programs that are innovative and in demand in the local or global markets, many students even from foreign countries will enroll. Hence, curriculum development matters a lot in setting the direction of change in an organization, not only at the micro but also at macro levels. As long as the goals and objectives of curriculum development are clear in the planner's mind, cutting-edge achievements in various concerns can be realized.

\section{A Guide to Curriculum Development: Purposes, Practices, Procedures}

The purpose of this guide is to provide some general instructions to school districts as staff begin to develop or revise their curriculum guides.

\section{Overview}

A curriculum guide is a structured document that delineates the philosophy, goals, objectives, learning experiences, instructional resources and assessments that comprise a specific educational program. Additionally, it represents an articulation of what students should know and be able to do and supports teachers in knowing how to achieve these goals. Accordingly, an exemplary guide is a tool that assists in planning and implementing a high quality instructional program. It:

- establishes sequences both within and between levels and assures a coherent and articulated progression from grade to grade;

- outlines a basic framework for what to do, how to do it, when to do it and how to know if it has been achieved;

- allows for flexibility and encourages experimentation and innovation within an overall structure;

- promotes interdisciplinary approaches and the integration of curricula when appropriate;

- suggests methods of assessing the achievement of the program's goals and objectives;

- Provides a means for its own ongoing revision and improvement.

The formulation of such a school or district curriculum guide should not be viewed as the culmination of the curriculum development process, but rather as an essential step in the process of ongoing curriculum development and implementation. Thus, no guide will be perfect. This acceptance will be far easier to attain when the curriculum guide is:

- consistent with what is known about child growth and development;

- compatible with the general philosophy of the school system; based upon clear convictions about teaching and learning;

- representative of instructional activities to meet the needs of students with varying abilities and needs;

- articulated from kindergarten through grade 12 ;

- easy to use by all educators;

- filled with samples, examples, and suggested resources;

- Linked to teacher evaluation goals and professional development.

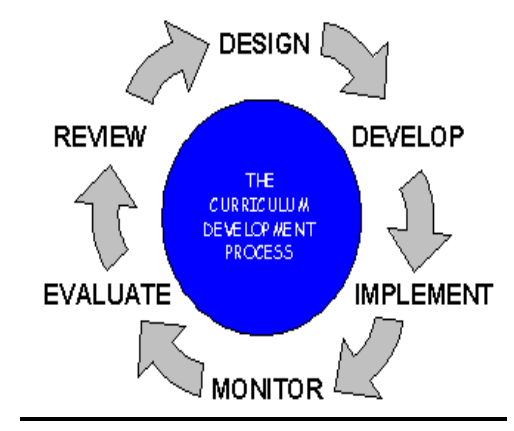

\section{The Curriculum Development Process}

The development of an effective curriculum guide is a multi-step, ongoing and cyclical process. The process progresses from evaluating the existing program, to designing an improved program, to implementing a new program and back to evaluating the revised program.Many schools carry out this process in a planned and systematic manner that includes the eleven components. Each of these components is addressed in the sections that follow. 


\section{Components of an Effective Curriculum Development Process}

A. Planning:

1. Convening a Curriculum Development Committee

2. Identifying Key Issues and Trends in the Specific Content Area

3. Assessing Needs and Issues

\section{B. Articulating and Developing:}

4. Articulating a K-12 Program Philosophy

5. Defining K-12 Program, Grade-Level and Course Goals

6. Developing and Sequencing of Grade-Level and Course Objectives

7. Identifying Resource Materials to Assist with Program Implementation

8. Developing and/or Identifying Assessment Items and Instruments to Measure Student Progress

\section{Implementing:}

9. Putting the New Program into Practice

\section{Evaluating:}

10. Updating the Program

11. Determining the Success of the Program

\section{A. Planning :}

1. Convening a Curriculum Development Committee. Such a committee, consisting primarily of teachers who represent the various schools and grade levels in a district, administrators, members of the public and perhaps students, becomes the driving force for curriculum change and the long-term process of implementing the curriculum.

2. Identifying Key Issues and Trends in the Specific Content Area. The first step in any curriculum development process involves research that reviews recent issues and trends of the discipline, both within the district and across the nation. This research allows a curriculum committee to identify key issues and trends that will support the needs assessment that should be conducted and the philosophy that should be developed.

Research often begins with a committee's reading and discussing timely, Committee members should examine what is currently being taught in the curriculum. They should examine state and national standards in the discipline. In addition, the committee should become familiar with newly available instructional materials particularly those that may eventually be adopted to help implement the new curriculum. Committee members should also broaden their perspective and gather information by visiting other school systems that are recognized leaders in education. As a result of this process, committee members are likely to identify many of the following issues and trends that will need to be addressed as the curriculum development process moves forward:

- meeting the needs of all students;

- learning theory and other cognitive psychology findings on how students learn;

- the current expectations of the field;

- the knowledge of and readiness for change on the part of teachers;

- the availability of resources;

- the role and availability of information and technology resources;

- scheduling issues;

- Methods and purpose of assessments; and

- Professional development

\section{Assessing Need and Issues.}

Curriculum development should be viewed as a process by which meeting student needs leads to improvement of student learning. Regardless of the theory or model followed, curriculum developers should gather as much information as possible. This information should include the desired outcomes or expectations of a high quality program, the role of assessment, the current status of student achievement and actual program content. The information should also consider the concerns and attitudes of teachers, administrators, parents and students. The data should include samples of assessments, lessons from teachers, assignments, textbooks currently used, student perception and feedback from parents. Whatever the particular circumstances, an 
effective curriculum development process usually entails a structured needs assessment to gather information and guide the curriculum development process.

The information, commonly gathered through surveys, structured discussions and test data, most frequently includes:

- teacher analysis of the present curriculum to identify strengths, weaknesses, omissions and/or problems;

- sample lessons that illustrate curriculum implementation;

- sample assessments that illustrate the implementation of the curriculum;

- Identification of what teachers at each grade level perceive to be the most serious issues within the curriculum.

\section{B. Articulating and Developing}

1. Articulating a K-12 Program Philosophy.

The program philosophy provides a unifying framework that justifies and gives direction to discipline based instruction.

After having studied curriculum trends and assessed the current program, curriculum developers should be ready to construct a draft philosophy guiding the K-12 program. Such a philosophy or set of beliefs should be more than just "what we think should be happening," but rather "what our curriculum is actually striving to reflect."

An effective philosophy statement has the following characteristics:
A. Accuracy:
B. Linkages
C. Breadth and Depth
D. Usefulness

\section{Defining K-12 Program, Grade-Level and Course Goals.}

The purpose of the K-12 program philosophy is to describe the fundamental beliefs and inform the process of instruction. The curriculum guide delineates K-12 program goals as well as grade-level and course goals that address the key cognitive and affective content expectations for the program.

\section{Developing and Sequencing of Grade-Level and Course Objectives.}

If the philosophy and goals of a curriculum represent the guiding principles of the curriculum, then the grade-level and course objectives represent the core of the curriculum. The specific grade-level and course objectives include clear expectations for what each learner is expected to know and be able to do and how it will be measured. Often, an effective guide will incorporate more than one format. For example, a common arrangement lists objectives grouped by strand within each grade level. In this manner the third grade teacher is provided with a complete listing of the third grade objectives organized by strand or major topic. However, it is important for this teacher to have access to the second grade objectives containing skills that may have been introduced, but not taught for mastery, as well as forthcoming fourth grade objectives. This information is often provided in a scope and sequence listing by strand that would place a specific third grade objective, for example, in the context of the entire K-8 strand. Thus, one of the most important roles of grade-level and course objectives is assuring smooth transitions and curricular coordination among levels, particularly between elementary schools and middle schools, and between middle schools and high schools.

In addition to the delineation and sequencing of content through objectives, many curriculum guides provide additional information to help teachers more effectively implement the curriculum

Accordingly, curriculum developers have a range of options for formatting and designing an effective curriculum guide.

4. Identifying Resource Materials to Assist with Program Implementation. An effective curriculum guide goes beyond a listing of objectives and identifies suggested instructional resources to help answer the question, "What instructional materials are available to help me meet a particular objective or set of objectives?" As teachers and programs move away from a single textbook approach and employ a broad range of supplementary materials, instructional modules for particular units, computer software and the like, it is increasingly important that the curriculum guide suggests and links available resources to curriculum objectives.

5. Developing and/or Identifying Assessment Items and Instruments to Measure Student Progress. This piece of the curriculum development process helps to focus instruction and ensures the often elusive, but critical, alignment of curriculum, instruction and assessment. Essentially the assessment piece of a curriculum is what drives curriculum. The assessments measure not only student progress, but also the effectiveness of the goals and objectives of the curriculum in meeting student needs. 
Common grade-level, course criterion-referenced assessments and performance-based assessments should be created along with the curriculum and become part of the curriculum guide itself. They help to clarify exactly what the grade or course objectives mean and provide a common standard for evaluating how successfully they are achieved.

\section{Implementing}

1. Putting the New Program into Practice. Too often, traditional practice entails sending a committee away for several after-school meetings and two weeks of summer writing as prelude to a back-to-school unveiling and distribution of the updated or revised curriculum. Instead of assuming that the process ends with the publication of a new guide, an effective curriculum committee continues to oversee the implementation, updating and evaluation of the curriculum.It is important to remember that any innovation introduced into a system - including a new curriculum -requires time and support to be fully implemented. First, teachers need time and opportunities to become aware of the new curriculum and its overall design, particularly how it differs from the past. Then teachers need time and opportunities to become familiar with the new curriculum - often school or grade level sessions that focus on those specific parts of the curriculum for which individuals are responsible. Next, teachers need at least two years to pilot the new curriculum and new materials in their classrooms. It is critical that the curriculum development committee, resource teachers and principals are aware of this process and are available to nurture it.

\section{Evaluating}

1. Updating the New Program. One of the most common methods of periodically updating a curriculum guide is through grade-level meetings designed to share materials, activities, units, assessments and even student work that support the achievement of the curriculum goals that were unknown or unavailable when the guide was first developed. These approaches are invaluable professional development opportunities wherein teachers assume ownership of the curriculum they are responsible for implementing. In this way, the guide becomes a growing resource for more effective program implementation.

2. Determining the Success of the New Program. The curriculum development cycle ends and then begins again with a careful evaluation of the effectiveness and impact of the program. Using surveys, focused discussions and meetings like those described in section 3, a curriculum development committee needs to periodically gather data on perceptions of program strengths, weaknesses, needs, preferences for textbooks and other materials, and topics or objectives that do not seem to be working effectively. This information should be gathered from data that represents overall student performance that is linked closely to daily instruction. Teams of teachers responsible for the specific discipline could accomplish this by sharing samples of assessments, performance tasks, student work, lessons and instructional practices related to the curricula.

\section{REFERENCES:}

[1] Robin Wolven, (2013) "Curriculum development resources for teachers and school librarians: a selection of resources", Reference Reviews, Vol. 27 Iss: 6, pp.4 - 9

[2] Bilbao, P. P., Lucido, P. I., Iringan, T. C., and R. B. Javier (2008). Curriculum development. Philippines: Lorimar Publishing, Inc.

[3] Jack C. Richards, Curriculum Development in Language Teaching (Cambridge Language Education) Kindle Edition 